\title{
Genetic variance in micro-environmental sensitivity for milk and milk quality in Walloon Holstein cattle
}

\author{
J. Vandenplas, ${ }^{*} \dagger^{1}$ C. Bastin, ${ }^{*}$ N. Gengler, ${ }^{*}$ and H. A. Mulder $¥ \S$ \\ ${ }^{*}$ Animal Science Unit, Gembloux Agro Bio-Tech, University of Liege, 5030 Gembloux, Belgium \\ †National Fund for Scientific Research, 1000 Brussels, Belgium \\ ¥Animal Breeding and Genomics Centre, Wageningen UR Livestock Research, PO Box 65, 8200 AB, Lelystad, the Netherlands \\ $\S$ Animal Breeding and Genomics Centre, Wageningen University, PO Box 338, 6700 AH Wageningen, the Netherlands
}

\begin{abstract}
Animals that are robust to environmental changes are desirable in the current dairy industry. Genetic differences in micro-environmental sensitivity can be studied through heterogeneity of residual variance between animals. However, residual variance between animals is usually assumed to be homogeneous in traditional genetic evaluations. The aim of this study was to investigate genetic heterogeneity of residual variance by estimating variance components in residual variance for milk yield, somatic cell score, contents in milk (g/ $\mathrm{dL}$ ) of 2 groups of milk fatty acids (i.e., saturated and unsaturated fatty acids), and the content in milk of one individual fatty acid (i.e., oleic acid, C18:1 cis-9), for first-parity Holstein cows in the Walloon Region of Belgium. A total of 146,027 test-day records from 26,887 cows in 747 herds were available. All cows had at least 3 records and a known sire. These sires had at least 10 cows with records and each herd $\times$ testday had at least 5 cows. The 5 traits were analyzed separately based on fixed lactation curve and random regression test-day models for the mean. Estimation of variance components was performed by running iteratively expectation maximization-REML algorithm by the implementation of double hierarchical generalized linear models. Based on fixed lactation curve test-day mean models, heritability for residual variances ranged between $1.01 \times 10^{-3}$ and $4.17 \times 10^{-3}$ for all traits. The genetic standard deviation in residual variance (i.e., approximately the genetic coefficient of variation of residual variance) ranged between 0.12 and 0.17 . Therefore, some genetic variance in micro-environmental sensitivity existed in the Walloon Holstein dairy cattle for the 5 studied traits. The standard deviations due to herd $\times$ test-day and permanent environment in residual variance ranged between 0.36 and 0.45 for herd $\times$ testday effect and between 0.55 and 0.97 for permanent
\end{abstract}

Received December 22, 2012.

Accepted June 7, 2013.

${ }^{1}$ Corresponding author: jvandenplas@ulg.ac.be environmental effect. Therefore, nongenetic effects also contributed substantially to micro-environmental sensitivity. Addition of random regressions to the mean model did not reduce heterogeneity in residual variance and that genetic heterogeneity of residual variance was not simply an effect of an incomplete mean model.

Key words: heterogeneity, residual variance, microenvironmental sensitivity

\section{INTRODUCTION}

In the current dairy industry, it is desirable that dairy cows are robust to environmental changes for some traits. If these environmental effects are unknown, genetic variation in micro-environmental sensitivity could be studied through genetic variance in residual variance. This is distinguished from genetic variation in macro-environmental sensitivity caused by known environmental factors, such as temperature (Mulder et al., 2013). In current genetic evaluations, residual variance is usually assumed homogeneous between animals. However, if genetic variation in micro-environmental sensitivity exists, the residual variance is heterogeneous between animals and can be called genetic heterogeneity of residual variance. Genetic heterogeneity of residual variance could be considered as a trait with a low heritability and used to improve robustness by selection (Mulder et al., 2007, 2008). Mulder et al. (2009) proposed a model including genetic heterogeneity of residual variance to quantify the genetic variance in residual variance in broilers. Rönnegård et al. (2010) proposed a double hierarchical generalized linear model (DHGLM) to estimate variance components and breeding values in the residual variance part. They showed that this model can be implemented on large data sets through software used by the current dairy industry. The DHGLM method was later extended by Felleki et al. (2012) to estimate correlations between random effects for the mean and residual variance parts. Using such models, selection for uniformity in the dairy industry can be performed through breed- 
ing values explaining genetic heterogeneity in residual variance.

To our knowledge, in dairy cows, only milk yield and SCS have been studied with regard to their environmental sensitivity (Rönnegård et al., 2011, 2013). These studies showed that the estimation of variance components and breeding values for large dairy data using current software was feasible. These authors also concluded that genetic variance in residual variance existed for both milk yield and SCS in Swedish Holstein cattle and that selection for decreased or increased environmental sensitivity could be feasible. Certainly, selection to change environmental sensitivity is of interest for other traits; for example, to increase homogeneity of milk products. Therefore, it could be of interest to investigate genetic variation in environmental sensitivity of dairy cows for other traits.

In addition to milk yield and SCS, this study focused on 2 major groups of milk FA, SFA and unsaturated FA (UFA), as well as on the oleic acid (C18:1 cis-9), to investigate the opportunity to select for uniformity in milk FA. Indeed, composition of milk FA has recently gained interest from the dairy industry because it influences the sensory, technological, and nutritional properties of dairy products. Higher content in milk of UFA and especially higher content of C18:1 cis-9 (which is the major UFA in milk) are considered to be healthier for humans, whereas 2 of the major SFA (i.e., C14:0 and C16:0) have been associated with increased levels of cholesterol and increased risk of cardiovascular disease (Williams, 2000; Haug et al., 2007). However, high amounts of UFA have been found to alter milk fat quality (Palmquist et al., 1993). Also, high levels of C18:1 cis-9 in early lactation are associated with body fat mobilization (Barber et al., 1997) and poorer fertility performance (Bastin et al., 2012). Therefore, a lower environmental sensitivity for C18:1 cis-9 in early lactation (i.e., less variation in the mobilization of adipose FA) would be desirable, in addition to a higher content of $\mathrm{C} 18: 1$ cis-9 in milk during the whole lactation (i.e., an improvement of the nutritional quality of milk fat). It could be suggested, therefore, that FA are traits with an intermediate optimum. In such cases, a nonlinear profit function is assumed, which leads to an interest in selection for uniformity for these traits. Mulder et al. (2008) showed that selection to change the variance of traits is economically of interest when the profit equation is nonlinear; that is, when the economic value of variance is nonzero.

The aim of this research was to study genetic heterogeneity of residual variance by the estimation of variance components and breeding values in residual variance for milk yield, SCS, SFA, UFA, and C18:1 cis9 for first-parity Holstein cows in the Walloon Region of Belgium. Fixed lactation curve and random regression test-day models were also compared.

\section{MATERIALS AND METHODS}

\section{Data Description}

Test-day records for milk yield $(\mathrm{kg})$ and SCS of Holstein cattle were extracted from the database used for the Walloon genetic evaluation of production traits. Only records between 5 and 365 DIM from first-parity Holstein cows, which were at least 21 mo old at first calving, were selected. In addition, only records where observations were between 3 and $85 \mathrm{~kg}$ for milk yield and between 0.1 and 9.6 for SCS were used.

To quantify fat and protein contents, milk samples that are collected through routine milk recording organized by the Walloon Breeding Association (Ciney, Belgium) are analyzed by a mid-infrared MilkoScan FT6000 spectrometer (Foss, Hillerød, Denmark). Since 2007, most of the generated spectral data have been stored in a database that is used to obtain predicted FA contents in milk ( $\mathrm{g} / \mathrm{dL}$ of milk) by applying the calibration equations developed by Soyeurt et al. (2011). Fatty acid contents used in this study were reliably predicted. Further details concerning the accuracies of the predictions are provided in Soyeurt et al. (2011). To avoid abnormal values in this study, predicted FA values below the 1st percentile and above the 99th percentile were deleted.

All cows included in the data set had at least 3 testday records with all milk yield, SCS, and FA records. All records from cows without a known sire were deleted, and the sires were required to have at least 10 cows with test-day records. Each herd $\times$ test-day was required to have at least 5 cows. These edits aimed to allow the differentiation between random effects on mean model and random effects on residual variance model (Mulder et al., 2009; Hill and Mulder, 2010). After edits, 146,027 test-day records (collected between January 2007 and April 2011) from 26,887 Walloon Holstein first-parity cows in 747 herds were included in the data set. The pedigree file extracted from the database used for the official Walloon genetic evaluation contained 86,410 animals. Pedigree data were limited to animals born after 1985. Descriptive statistics of data after edits are presented in Table 1.

\section{Statistical Model}

The 5 traits, milk yield, SCS, and contents in milk (g/ dL of milk) of SFA, UFA, and C18:1 cis-9 were analyzed separately. Estimation of variance components and breeding values was performed by running iteratively 
Table 1. Descriptive statistics of the data set after edits for both mean models and of the data set used for estimation of variance components and breeding values based on the fixed lactation curve test-day mean model for milk yield, SCS, SFA, unsaturated fatty acid (UFA), and C18:1 cis-9 contents in milk

\begin{tabular}{|c|c|c|c|c|c|c|c|c|c|c|c|}
\hline \multirow[b]{2}{*}{ Trait } & \multicolumn{4}{|c|}{ Data set after edits } & \multicolumn{7}{|c|}{ Data set for estimation ${ }^{1}$} \\
\hline & Mean & SD & Minimum & Maximum & Mean & $\mathrm{SD}$ & Minimum & Maximum & $\sigma_{e_{p}}^{2}$ & $h_{v}^{2}$ & GCV \\
\hline SCS & 2.54 & 1.52 & 0.10 & 9.64 & 2.47 & 1.48 & 0.10 & 9.37 & 0.79 & $3.47 \times 10^{-3}$ & 0.16 \\
\hline SFA & 2.79 & 0.46 & 1.65 & 4.25 & 11.63 & 1.91 & 6.90 & 17.75 & 0.82 & $1.01 \times 10^{-3}$ & 0.12 \\
\hline UFA & 1.31 & 0.23 & 0.84 & 2.34 & 9.40 & 1.62 & 6.00 & 16.83 & 0.84 & $3.57 \times 10^{-3}$ & 0.12 \\
\hline C18:1 cis-9 & 0.80 & 0.17 & 0.45 & 1.67 & 7.40 & 1.57 & 4.16 & 15.36 & 0.85 & $4.17 \times 10^{-3}$ & 0.12 \\
\hline
\end{tabular}

${ }^{1}$ All observations of each trait were divided by the square root of the corresponding homogeneous residual variance. Average residual variances in the population; that is, average of inverted weights used by the mean model $\left(\sigma_{e_{p}}^{2}\right)$, and heritabilities $\left(h_{v}^{2}\right)$ and genetic coefficients of variation (GCV) for residual variances. Homogeneous residual variances were equal to 1.00 for all traits.

expectation maximization (EM)-REML algorithm by implementation of DHGLM method (Rönnegård et al., 2010). The applied model was split between the mean and the residual variance. To model the mean, a fixed lactation curve test-day model was used at first (mean model [1]). Estimations were then performed using a random regression test-day model (mean model [2]) to study the effect of using a more or less complete mean model on genetic variance in residual variance. The mean model [1] was a fixed lactation curve test-day model:

$$
\mathbf{y}=\mathbf{X} \boldsymbol{\beta}+\mathbf{Z}_{\mathrm{u}} \mathbf{u}+\mathbf{Z}_{\mathrm{p}} \mathbf{p}+\mathbf{e}
$$

where $\mathbf{y}$ is the vector of records, $\boldsymbol{\beta}$ is the vector of fixed effects for the mean [i.e., herd $\times$ test-day, lactation stage (classes of 5 DIM), gestation stage, and age at calving $\times$ season of calving $\times$ major lactation stage $(5$ classes of $73 \mathrm{DIM})$ ], $\mathbf{u}$ is the vector of random additive genetic effects for the mean, $\mathbf{p}$ is the vector of random permanent environmental effects for the mean, and $\mathbf{e}$ is the vector of residuals; $\mathbf{X}, \mathbf{Z}_{\mathbf{u}}$, and $\mathbf{Z}_{\mathbf{p}}$ are incidence matrices relating records to fixed effects, random additive genetic effects, and random permanent environmental effects, respectively. The gestation stage was defined following available dates of insemination and dates of end of lactation. If both dates were unknown, gestation stage was defined as unknown.

The mean model [2] was a random regression testday model defined as follows:

$$
\mathbf{y}=\mathbf{X}_{\mathrm{RR}} \boldsymbol{\beta}_{\mathrm{RR}}+\mathbf{Q}\left(\mathbf{z}_{\mathrm{u}_{\mathrm{RR}}} \mathbf{u}_{\mathrm{RR}}+\mathbf{Z}_{\mathrm{p}_{\mathrm{RR}}} \mathbf{p}_{\mathrm{RR}}\right)+\mathbf{e}_{\mathrm{RR}}
$$

where $\boldsymbol{\beta}_{\mathbf{R R}}$ is the vector of fixed effects for the mean [i.e., herd $\times$ test-day, lactation stage (classes of 5 DIM), gestation stage, and age at calving $\times$ season of calving $\times$ major lactation stage ( 5 classes of $73 \mathrm{DIM})], \mathbf{u}_{\mathbf{R R}}$ is the vector of additive genetic random regression coeffi- cients for the mean, $\mathbf{p}_{\mathbf{R R}}$ is the vector of permanent environmental random regression coefficients for the mean, and $\mathbf{e}_{\mathbf{R R}}$ is the vector of residuals; $\mathbf{X}_{\mathbf{R R}}, \mathbf{Z}_{\mathbf{u}_{\mathbf{R}}}$, and $\mathbf{Z}_{\mathrm{p}_{\mathrm{RR}}}$ are incidence matrices relating records to effects. The matrix $\mathbf{Q}$ is the covariate matrix for secondorder Legendre polynomials, which are used to model regression curves, as in previous studies conducted on similar data sets (Bastin et al., 2011, 2012).

Concerning the model for residual variance, the distributions of $\mathbf{e}$ and $\mathbf{e}_{\mathbf{R R}}$ were assumed to be independently normal with heterogeneous variance. The applied residual variance model associated with both mean models [1] and [2] was

$$
V(\mathbf{e})=\exp \left(\mathbf{X}_{\mathbf{v}} \boldsymbol{\beta}_{\mathbf{v}}+\mathbf{Q}_{\mathbf{v}} \mathbf{h}_{\mathbf{v}}+\mathbf{Z}_{\mathbf{u}_{\mathrm{v}}} \mathbf{u}_{\mathbf{v}}+\mathbf{Z}_{\mathbf{p}_{\mathbf{v}}} \mathbf{p}_{\mathbf{v}}\right)
$$

where $\boldsymbol{\beta}_{\mathbf{v}}$ is the vector of fixed effects for residual variance [i.e., herd $\times$ calving year, lactation stage (classes of 5 DIM), gestation stage, and age at calving $\times$ season of calving $\times$ major lactation stage $(5$ classes of 73 DIM)], $\mathbf{h}_{\mathbf{v}}$ is the vector of random herd $\times$ test-day effects, $\mathbf{u}_{\mathbf{v}}$ is the vector of random additive genetic effects for residual variance, and $\mathbf{p}_{\mathrm{v}}$ is the vector of random permanent environmental effects for residual variance; $\mathbf{X}_{\mathbf{v}}, \mathbf{Q}_{\mathbf{v}}, \mathbf{Z}_{\mathbf{u}_{\mathrm{v}}}$, and $\mathbf{Z}_{\mathbf{p}_{\mathbf{v}}}$ are incidence matrices relating records to fixed and random effects.

Herd $\times$ test-day effects were modeled in the residual variance models as random effects because their estimation was more robust than estimation as a fixed effect due to the small number of observations in each herd $\times$ test-day classes. Modeling herd $\times$ time effects as random is very common in variance models (e.g., Meuwissen et al., 1996).

For this research and following the DHGLM method proposed by Rönnegård et al. (2010), we assumed that $\mathbf{u}$ and $\mathbf{u}_{\mathbf{v}}$ followed a multivariate normal (MVN) distribution, 


$$
\operatorname{MVN}\left([\mathbf{0}],\left[\begin{array}{cc}
\mathbf{A} \sigma_{u}^{2} & \mathbf{0} \\
\mathbf{0}
\end{array}\right]\right),
$$

where the matrix $\mathbf{A}$ is the pedigree-based relationship matrix, and $\sigma_{u}^{2}$ and $\sigma_{u_{v}}^{2}$ are the additive genetic variances for mean and residual variance, respectively. We also assumed that $\mathbf{p}$ and $\mathbf{p}_{\mathbf{v}}$ followed a multivariate normal distribution,

$$
M V N\left(\left[\begin{array}{l}
\mathbf{0} \\
\mathbf{0}
\end{array}\right],\left[\begin{array}{cc}
\mathbf{I} \sigma_{p}^{2} & \mathbf{0} \\
\mathbf{0} & \mathbf{I} \sigma_{p_{v}}^{2}
\end{array}\right]\right),
$$

where $\mathbf{I}$ is the identity matrix, $\sigma_{p}^{2}$ and $\sigma_{p_{v}}^{2}$ are the random permanent environmental variances for mean and residual variance, respectively, and $\mathbf{h}_{\mathrm{v}}$ followed a multivariate normal distribution $\operatorname{MVN}\left(0, \mathbf{I} \sigma_{h_{v}}^{2}\right)$, where $\sigma_{h_{v}}^{2}$ is the herd-test-day variance for residual variance.

No correlations were assumed between $\mathbf{p}$ and $\mathbf{p}_{\mathbf{v}}$ or between $\mathbf{u}$ and $\mathbf{u}_{\mathbf{v}}$. Genetic correlations between $\mathbf{u}$ and $\mathbf{u}_{\mathbf{v}}$ have been demonstrated as relevant parameters (e.g., SanCristobal-Gaudy et al., 2001; Sorensen and Waagepetersen, 2003), and Felleki et al. (2012) extended the DHGLM method by Rönnegård et al. (2010) to include correlations between random effects for mean and residual variance models. However, as explained below, the variance components estimation software used for this study did not allow implementation of the extended algorithm by Felleki et al. (2012). Furthermore, previous studies showed, based on their own data, that variance component estimates were approximately the same if the model with heterogeneous residual variance did or did not include a genetic correlation between $\mathbf{u}$ and $\mathbf{u}_{\mathbf{v}}$ (e.g., Rönnegård et al., 2010). Similar variance components were also estimated when the genetic correlation was arbitrarily set to zero (SanCristobal-Gaudy et al., 2001). The same assumptions were applied to the random regression test-day models.

Estimation of variance components and breeding values was performed using REMLF90 (Misztal, 2012) applying EM-REML and modified to implement the DHGLM method by Rönnegård et al. (2010). The algorithm iterated between 2 models - the mean model and the residual variance model. First, a weighted animal mixed model for the mean model was fitted, where the weights adjusted for residual variance differences. Second, the adjusted squared residuals from the mean model were fitted for the residual variance model using a weighted animal generalized linear model. Weights for the residual variance model were functions of leverages of the previous fitted mean model. Third, the ex- pected residual variances per observation based on the solutions of the residual variance model were used to update weights for the mean model to start the second iteration. These iterations between these 2 models were performed until convergence. Although REMLF90 was modified to implement the DHGLM method by Rönnegård et al. (2010), these modifications did not allow the implementation of the extended DHGLM method proposed by Felleki et al. (2012). The reason is that the BLUPF90 family of programs (Misztal, 2012) allows the use of a single weight for all traits included in the model, whereas the bivariate extended DGHLM method requires different weights for the mean and residual variance models.

The convergence was achieved when convergence criteria; that is, the squared relative difference between consecutive estimates, was lower than $1 \times 10^{-8}$ for 10 consecutive iterations for both mean and residual variance models. For both mean models [1] and [2], starting values of variance components at the first iteration were estimated by REMLF90 using the corresponding mean model with a homogeneous residual variance on the used data set. Because BLUPF90 family of programs (Misztal, 2012) had some limitations concerning an appropriate inclusion of weights in the context of this study, standard errors of variance components were estimated using the average information (AI)-REML algorithm by fitting weighted animal models based on data from the last converged iteration.

To improve the numerical issues encountered for estimation of variance components and breeding values, some computational heuristics were performed. First, before implementing the DHGLM method, observations were standardized for each trait by dividing them by the square root of the residual variance estimated with a model with homogeneous residual variance. Homogeneous residual variances were then equal to 1.00 for all standardized traits. The standardizations limited variations of residual variances for both mean models during the first iterations. Descriptive statistics of standardized data sets used for estimation of variance components based on the mean model [1] are presented in Table 1. Second, after a period of 5 rounds where weights were computed for each iteration, weights used by both the mean and residual variance models were averages of weights estimated during the last 3 iterations, starting from the sixth round. The objective was to stabilize weights and to avoid too-large variations. Third, weights for the mean model higher than $1 \times 10^{7}$ were set to $1 \times 10^{7}$ to avoid singular matrices in the left-hand side of the mixed-model equations.

The comparison of the 4 different models; that is, fixed lactation curve test-day models (mean models [1]) with homogeneous or heterogeneous residual variance 
and random regression test-day models (mean models [2]) with homogeneous or heterogeneous residual variance, was based on statistical criteria derived from the h-likelihood theory for DHGLM (Lee and Nelder, 2006). At convergence, the 2 univariate estimations of variance components for both mean and residual variance models were equivalent to a bivariate estimation of variance components for both mean and residual variance models for which correlations were fixed to zero between $\mathbf{p}$ and $\mathbf{p}_{\mathbf{v}}$ and between $\mathbf{u}$ and $\mathbf{u}_{\mathbf{v}}$. Therefore, the adjusted profile h-likelihood (APHL) can be approximated from the log REML-likelihood $(\log \mathbf{L})$ of the bivariate model taking into account the fact that the adjusted squared residuals from the mean model were fitted for the residual variance model (Felleki et al., 2012; Mulder et al., 2013):

$$
A P H L=-2 \log L-\sum e_{v i}^{2} w_{v i} \sigma_{e_{v}}^{-2}-\sum \ln \left(\sigma_{e_{v}}^{2} / w_{v i}\right),
$$

where $e_{v i}$ and $w_{v i}$ are residual and weight for the variance model for the $i$ th observation, respectively, and $\sigma_{e_{v}}^{2}$ is the scaling residual variance for the residual variance model.

To compare the goodness of fit of a model, Akaike's information criterion (AIC; Akaike, 1973) was estimated based on the APHL (Mulder et al., 2013):

$$
A I C=A P H L+2 k,
$$

where $k$ is the number of variance parameters.

Bayesian's information criterion (BIC; Schwarz, 1978), a criterion for model selection among parametric models with different numbers of parameters, was estimated as follows:

$$
B I C=A P H L+k \ln (n),
$$

where $n$ is the number of observations.

For each statistical criterion (i.e., APHL, AIC, and $\mathrm{BIC})$, the model with the lowest statistical criterion is considered as the best.

Average residual variances in the population were defined for each of the 5 traits as

$$
\sigma_{e_{p}}^{2}=\operatorname{average}\left(\left(\operatorname{diag}(\mathbf{W}) \times \sigma_{e}^{2}\right)^{-1}\right),
$$

where $\mathbf{W}$ and $\sigma_{e}^{2}$ were the diagonal matrix of the weights and the residual variance used during the last converged mean model, respectively. Heritabilities of residual variances $\left(h_{v}^{2}\right)$ were calculated following the formula proposed by Mulder et al. (2007); that is, the regression of
$\mathrm{EBV}_{\mathrm{v}}$ on squared phenotype values. Genetic coefficients of variation $(\mathbf{G C V})$ for residual variances were approximated as the genetic standard deviations of the residual variance model (Mulder et al., 2007). All units of results were presented on the scale of the standardized traits and were expressed as standardized units (SU). Genetic correlations were approximated by Pearson correlation coefficients between EBV for the mean model $(\mathbf{E B V}=\mathbf{u})$ and EBV for the residual variance model $\left(\mathbf{E B V}_{\mathbf{v}}=\mathbf{u}_{\mathrm{v}}\right)$ for sires that had daughters with records, and for cows with records, for the 5 traits. Standard errors on these Pearson correlations were used to construct $95 \%$ confidence intervals. Reliabilities of both EBV and $\mathrm{EBV}_{\mathrm{v}}$ were computed from prediction error variances obtained from the inverse of the lefthand side of weighted animal models based on data from the last converged iteration. No corrections were performed for inbreeding.

\section{RESULTS AND DISCUSSION}

\section{Influence of a Random Regression Test-Day Mean Model and Comparison of Models}

To study the influence of the addition of random regressions to the mean model on the residual variance model, variance components in residual variance were estimated for the 5 traits based on both mean models. Variance components for the residual variance associated with the mean models [1] (i.e., $\sigma_{h_{v}}^{2}, \sigma_{p_{v}}^{2}$, and $\sigma_{u_{v}}^{2}$; Table 2) were in a slightly lower range than the variance components for the residual variance associated with the mean models [2] (i.e., $\sigma_{R R h_{v}}^{2}, \sigma_{R R p_{v}}^{2}$, and $\sigma_{R R u_{v}}^{2}$; Table 2). Heritabilities for the residual variance associated with the mean models [2] as well as GCV (results not shown) were similar to those for residual variance associated with the mean models [1]. The results showed that the addition of random regressions to the mean model did not reduce the genetic heterogeneity in residual variance and that genetic heterogeneity of residual variance was not simply an effect of an incomplete mean model.

The model selection criteria (i.e., APHL, AIC, and BIC; Table 3) also showed that the consideration of an heterogeneous residual variance for the mean models [2] fit better than these mean models with an homogeneous residual variance for the 5 traits, confirming that some genetic heterogeneity in residual variance existed for the 5 traits. This was also confirmed for the mean models [1], except for SFA, where the model selection criteria favored the mean model [1] with homogeneous residual variance. When homogeneous residual variance was assumed, mean model [1] was much better than 
Table 2. Variance components (SE in parentheses) estimated for milk yield, SCS, SFA, unsaturated fatty acid (UFA), and C18:1 cis-9 contents in milk using models with homogeneous or heterogeneous residual variance based on fixed lactation curve test-day mean models and variance components for the residual variance models estimated for the 5 traits based on random regression test-day mean models are presented

\begin{tabular}{|c|c|c|c|c|c|c|c|}
\hline \multirow[b]{2}{*}{ Model } & \multirow[b]{2}{*}{ Parameter } & \multirow{2}{*}{$\begin{array}{l}\text { Variance } \\
\text { component }^{1}\end{array}$} & \multicolumn{5}{|c|}{ Trait } \\
\hline & & & Milk yield & SCS & SFA & UFA & C18:1 cis-9 \\
\hline $\begin{array}{l}\text { Homogeneous residual variance } \\
\text { (fixed lactation curve test-day models) }\end{array}$ & Mean & $\begin{array}{l}\sigma_{p}^{2} \\
\sigma_{u}^{2}\end{array}$ & $\begin{array}{l}1.15 \\
\left(0.14 \times 10^{-1}\right) \\
0.55 \\
\left(0.15 \times 10^{-1}\right)\end{array}$ & $\begin{array}{l}0.76 \\
\left(0.85 \times 10^{-2}\right) \\
0.15 \\
\left(0.92 \times 10^{-2}\right)\end{array}$ & $\begin{array}{l}0.37 \\
\left(0.15 \times 10^{-1}\right) \\
1.27 \\
\left(0.18 \times 10^{-1}\right)\end{array}$ & $\begin{array}{l}0.15 \\
\left(0.92 \times 10^{-2}\right) \\
0.28 \\
\left(0.12 \times 10^{-1}\right)\end{array}$ & $\begin{array}{l}0.12 \\
\left(0.78 \times 10^{-2}\right) \\
0.19 \\
\left(0.98 \times 10^{-2}\right)\end{array}$ \\
\hline $\begin{array}{l}\text { Heterogeneous residual variance } \\
\text { (fixed lactation curve test-day models) }\end{array}$ & Mean & $\begin{array}{l}\sigma_{p}^{2} \\
\sigma_{u}^{2}\end{array}$ & $\begin{array}{l}1.11 \\
\left(0.43 \times 10^{-2}\right) \\
0.57 \\
\left(0.33 \times 10^{-1}\right)\end{array}$ & $\begin{array}{l}0.70 \\
\left(0.43 \times 10^{-2}\right) \\
0.15 \\
\left(0.15 \times 10^{-1}\right)\end{array}$ & $\begin{array}{l}0.41 \\
\left(0.43 \times 10^{-2}\right) \\
1.34 \\
\left(0.38 \times 10^{-1}\right)\end{array}$ & $\begin{array}{l}0.14 \\
\left(0.43 \times 10^{-2}\right) \\
0.30 \\
\left(0.11 \times 10^{-1}\right)\end{array}$ & $\begin{array}{l}0.11 \\
\left(0.43 \times 10^{-2}\right) \\
0.20 \\
\left(0.81 \times 10^{-2}\right)\end{array}$ \\
\hline & Residual variance & $\begin{array}{l}\sigma_{h_{v}}^{2} \\
\sigma_{p_{v}}^{2} \\
\sigma_{u_{v}}^{2}\end{array}$ & $\begin{array}{l}0.13 \\
\left(0.30 \times 10^{-2}\right) \\
0.53 \\
\left(0.65 \times 10^{-2}\right) \\
0.29 \times 10^{-1} \\
\left(0.41 \times 10^{-2}\right)\end{array}$ & $\begin{array}{c}0.18 \\
\left(0.40 \times 10^{-2}\right) \\
0.95 \\
\left(0.99 \times 10^{-2}\right) \\
0.25 \times 10^{-1} \\
\left(0.52 \times 10^{-2}\right)\end{array}$ & $\begin{array}{c}0.14 \\
\left(0.31 \times 10^{-2}\right) \\
0.42 \\
\left(0.55 \times 10^{-2}\right) \\
0.14 \times 10^{-1} \\
\left(0.28 \times 10^{-2}\right)\end{array}$ & $\begin{array}{l}0.20 \\
\left(0.43 \times 10^{-2}\right) \\
0.33 \\
\left(0.62 \times 10^{-2}\right) \\
0.15 \times 10^{-1} \\
\left(0.35 \times 10^{-2}\right)\end{array}$ & $\begin{array}{l}0.19 \\
\left(0.45 \times 10^{-2}\right) \\
0.30 \\
\left(0.63 \times 10^{-2}\right) \\
0.15 \times 10^{-1} \\
\left(0.38 \times 10^{-2}\right)\end{array}$ \\
\hline $\begin{array}{l}\text { Heterogeneous residual variance } \\
\text { (random regression test-day models) }\end{array}$ & Residual variance & $\begin{array}{l}\sigma_{R R h_{v}}^{2} \\
\sigma_{R R p_{v}}^{2} \\
\sigma_{R R u_{v}}^{2}\end{array}$ & $\begin{array}{l}0.20 \\
\left(0.34 \times 10^{-2}\right) \\
0.63 \\
\left(0.67 \times 10^{-2}\right) \\
0.35 \times 10^{-1} \\
\left(0.43 \times 10^{-2}\right)\end{array}$ & $\begin{array}{l}0.21 \\
\left(0.42 \times 10^{-2}\right) \\
1.02 \\
\left(0.10 \times 10^{-1}\right) \\
0.33 \times 10^{-1} \\
\left(0.59 \times 10^{-2}\right)\end{array}$ & $\begin{array}{l}0.18 \\
\left(0.33 \times 10^{-2}\right) \\
0.47 \\
\left(0.57 \times 10^{-2}\right) \\
0.17 \times 10^{-1} \\
\left(0.30 \times 10^{-2}\right)\end{array}$ & $\begin{array}{l}0.23 \\
\left(0.45 \times 10^{-2}\right) \\
0.34 \\
\left(0.64 \times 10^{-2}\right) \\
0.21 \times 10^{-1} \\
\left(0.42 \times 10^{-2}\right)\end{array}$ & $\begin{array}{l}0.22 \\
\left(0.46 \times 10^{-2}\right) \\
0.31 \\
\left(0.64 \times 10^{-2}\right) \\
0.18 \times 10^{-1} \\
\left(0.42 \times 10^{-2}\right)\end{array}$ \\
\hline
\end{tabular}

${ }^{1} \sigma_{p}^{2}$ and $\sigma_{u}^{2}$ are the random permanent environmental and additive genetic variances for mean, respectively; $\sigma_{h_{v}}^{2}, \sigma_{p_{v}}^{2}$, and $\sigma_{u_{v}}^{2}$ are the herd-test-day, random permanent environmental, and additive genetic variances for residual variance based on a fixed lactation curve test-day mean model; $\sigma_{R R h_{v}}^{2}, \sigma_{R R p_{v}}^{2}$, and $\sigma_{R R u_{v}}^{2}$ are the herd-test-day, random permanent environmental, and additive genetic variances for residual variance based on a random regression test-day model. 
Table 3. Model selection criteria for milk yield, SCS, SFA, unsaturated fatty acid (UFA), and C18:1 cis-9 contents in milk using models with homogeneous or heterogeneous residual variance based on fixed lactation curve or random regression test-day mean models

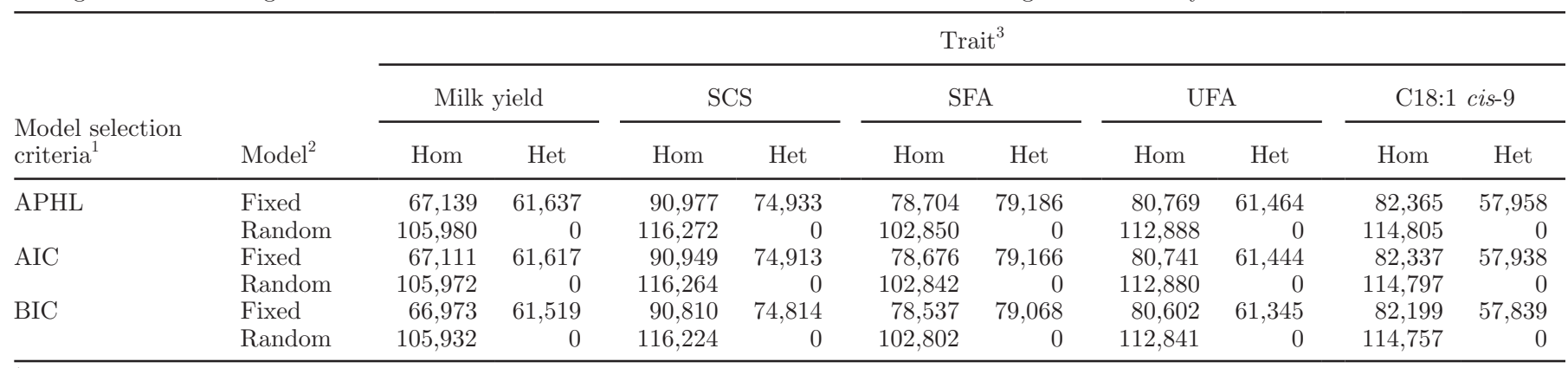

${ }^{1} \mathrm{APHL}=$ adjusted profile h-likelihood; AIC $=$ Akaike's information criterion; BIC $=$ Bayesian information criterion. The model selection criteria were expressed relative to the model selection criteria of the best model, which was put to zero.

${ }^{2}$ Fixed $=$ fixed lactation curve test-day mean model; Random $=$ random regression test-day mean model.

${ }^{3} \mathrm{Hom}=$ homogeneous residual variance; Het $=$ heterogeneous residual variance.

mean model [2] for all traits for all 3 model selection criteria. The extremely large differences in APHL between the mean model [2] with homogeneous or heterogeneous residual variance were unexpected. Therefore, we had more confidence in the results of the mean model [1] with heterogeneous variance. The following results will only concern those obtained from the estimations of variance components and breeding values in residual variance based on the mean model [1] with heterogeneous residual variance for the 5 traits.

\section{Heritabilities, Genetic Coefficients of Variation, and Variances}

For the 5 studied traits, fitting a model with heterogeneous residual variance based on the fixed lactation curve test-day mean model [1] increased the estimates for genetic variance for the mean (except for SCS) and decreased those for permanent environmental variance for the mean (except for SFA). Average residual variances in the population for the 5 traits ranged from 0.79 to 0.85 (Table 1 ), whereas homogeneous residual variances were set to 1.00 . Moreover, $h_{v}^{2}$ ranged from $1.01 \times 10^{-3}$ for SFA to $4.17 \times 10^{-3}$ for C18:1 cis-9 (Table 1 ). These $h_{v}^{2}$ were in the same range as those estimated by Rönnegård et al. (2013) for milk yield and SCS in Swedish Holstein dairy cattle. However, they were lower than estimates in other species, which ranged between 0.02 and 0.05 (Hill and Mulder, 2010). It should be noted that $h_{v}^{2}$ were similar and highest for UFA and C18:1 cis-9 $\left(\geq 3.57 \times 10^{-3}\right.$; Table 1$)$. The similarities between the results for UFA and C18:1 cis-9 can be explained by the high proportion of $\mathrm{C} 18: 1$ cis- 9 in UFA (Table 1). Furthermore, UFA and C18:1 cis-9 were genetically highly correlated (0.96; Table3; Bastin et al., 2011).
For all traits, GCV were low and ranged between 0.12 for FA traits and 0.17 for milk yield (Table 1 ), and standard errors of $\sigma_{u_{v}}^{2}$ ranged from $0.28 \times 10^{-2}$ to 0.52 $\times 10^{-2} \mathrm{SU}$ (Table 2). This range of GCV corresponded to the lower range of GCV for other species (Hill and Mulder, 2010). Rönnegård et al. (2013) presented GCV of 0.21 and 0.22 for SCS and milk yield, respectively, slightly higher than found in this study. Still, it seems that some genetic variance in environmental sensitivity existed for all studied traits in Walloon Holstein dairy cattle, indicating that environmental sensitivity could be changed by selection to a larger extent for milk yield and SCS than for FA traits. A change of 1 SD in EBV for one of the studied traits would alter the residual variance by $12 \%$ for FA traits to $18 \%$ for milk yield.

It is worth noting that low $h_{v}^{2}$ indicated that $\mathrm{EBV}_{\mathrm{v}}$ have to be estimated from a large data set with enough information per animal to be accurate (Mulder et al., 2007). This was confirmed by reliabilities of $\mathrm{EBV}_{\mathrm{v}}$ for sires having daughters with records (Figure 1). For both EBV and $\mathrm{EBV}_{\mathrm{v}}$, reliabilities increased with the number of daughters with records per sire. Some variations between sires could be observed for the same number of daughters because their daughters may differ in number of records. The average number of records per daughter was 5.4. Reliabilities of $\mathrm{EBV}_{\mathrm{v}}$ were lower than those of EBV for the same number of daughters with records. Based on selection index theory (Van Vleck, 1993) and the low $h_{v}^{2}$, these low reliabilities were expected. However, the calculated reliabilities also showed that selection on environmental sensitivity is possible if data from a large number of daughters per sire are available.

Figure 2 shows observations and the fitted mean curve for $\mathrm{C} 18: 1 \mathrm{cis}-9$ of 2 cows chosen to have the lowest or the highest $\mathrm{EBV}_{\mathrm{v}}$ and at least 8 records in the 
Milk yield

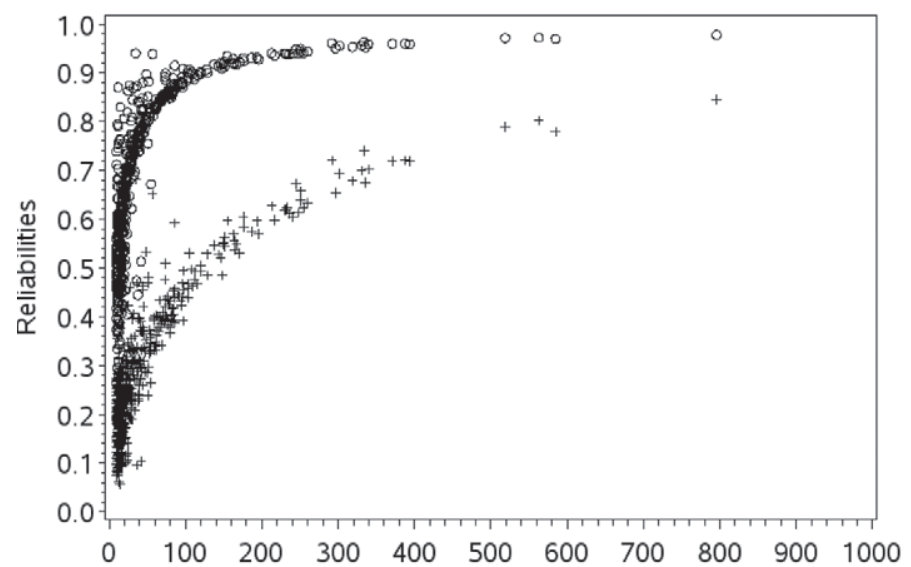

SFA

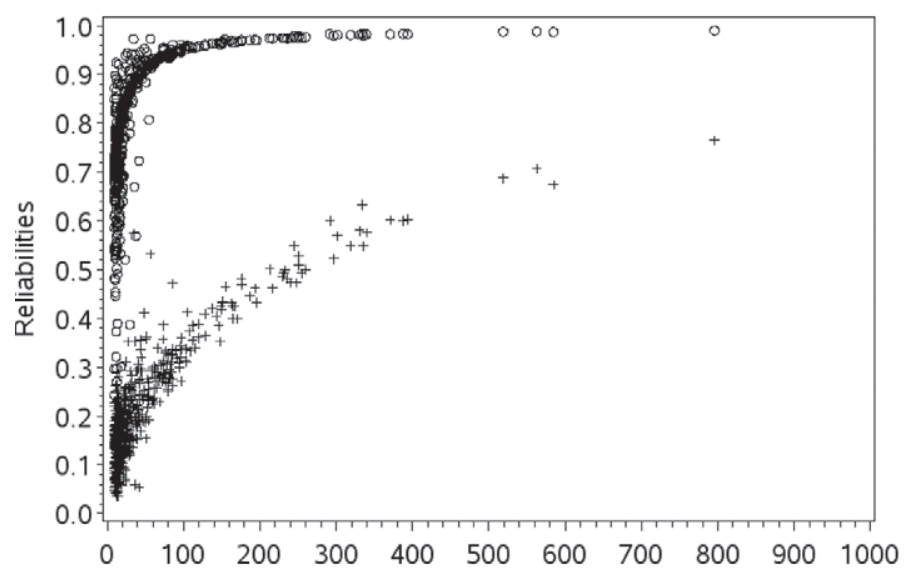

C18:1 cis-9

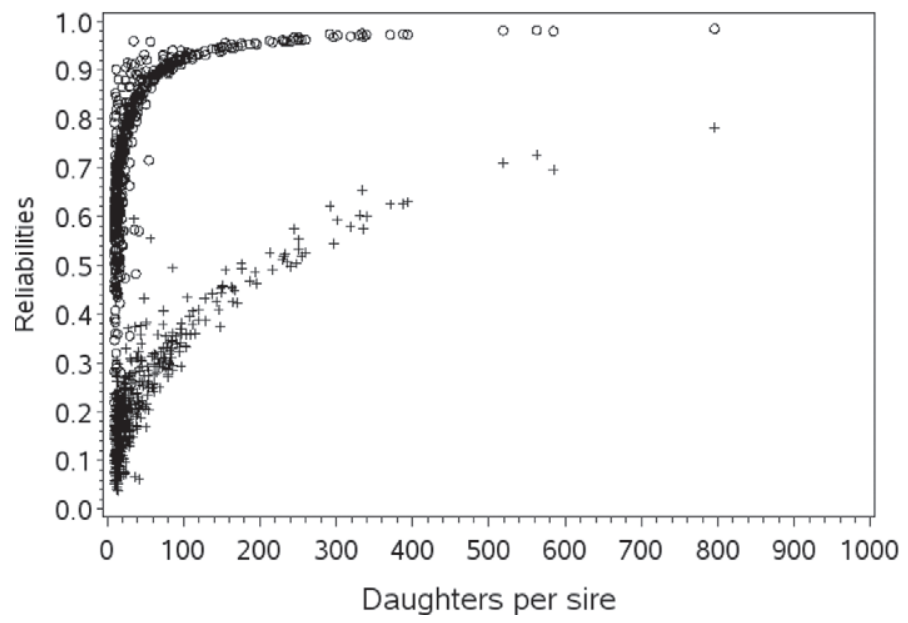

SCS

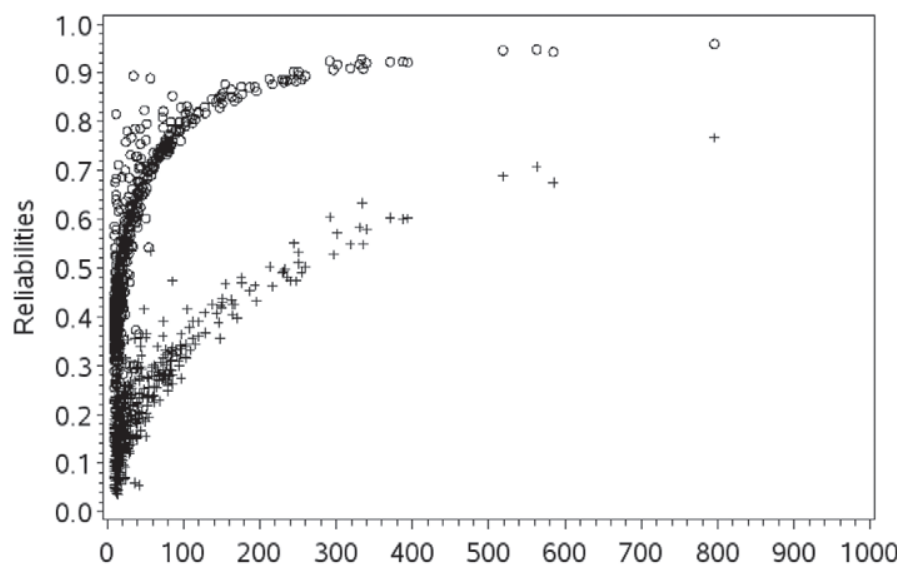

UFA

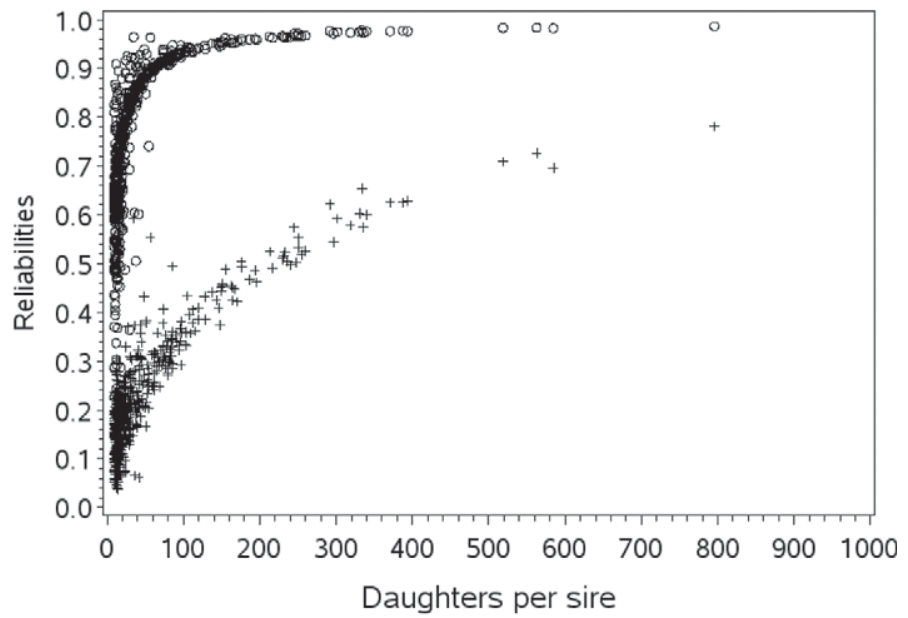

Figure 1. Reliabilities of EBV for the fixed lactation curve test-day mean model $(\bigcirc)$ and reliabilities of EBV for the associated residual variance model $(+)$ for milk yield, SCS, SFA, unsaturated fatty acid (UFA), and C18:1 cis-9 contents in milk in relation to the number of daughters with records per sire. 
Low EBVv cow

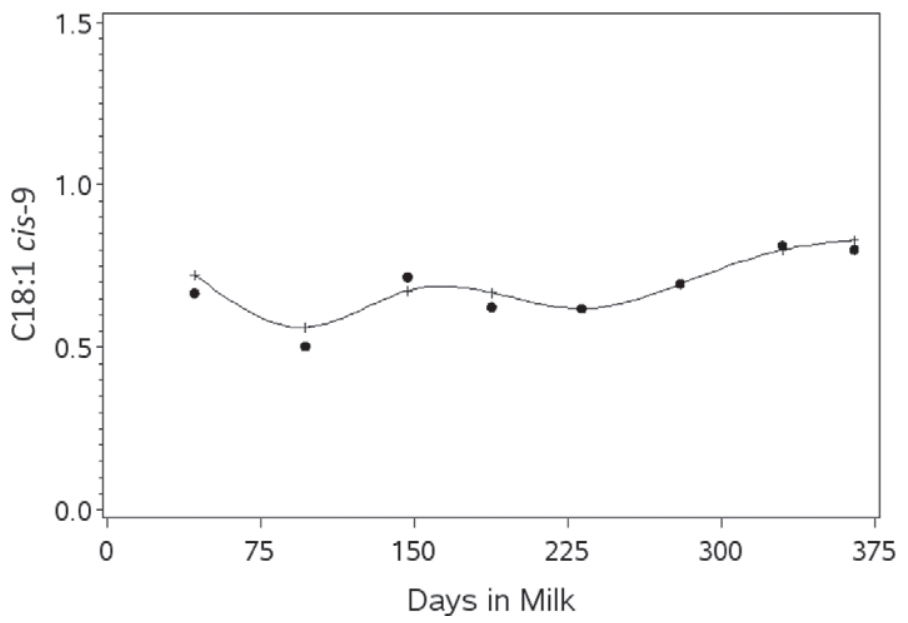

High EBVv cow

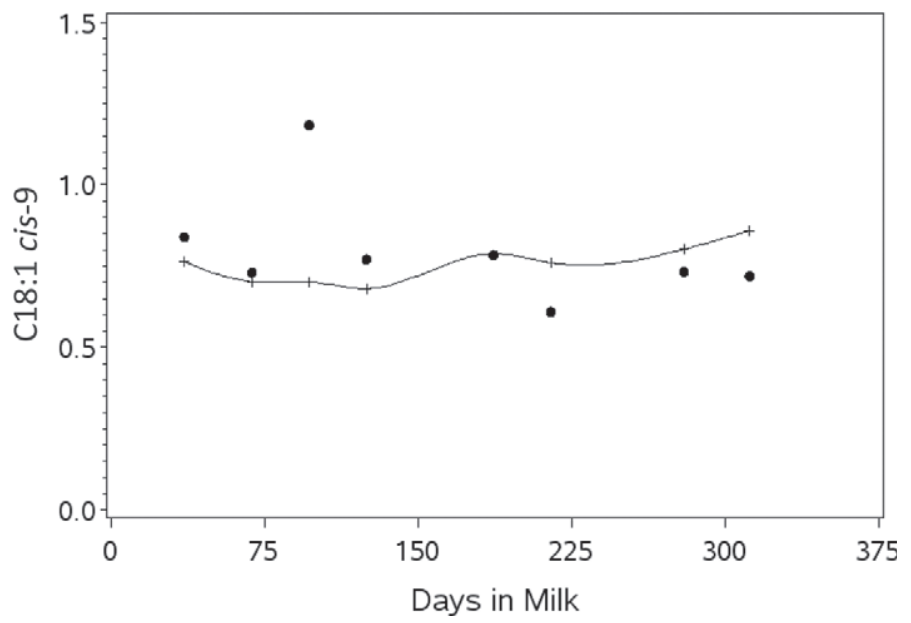

Figure 2. Observations $(\bullet)$ and fitted curve $(-)$ for a cow with a low EBV for the residual variance model $\left(\mathrm{EBV}_{\mathrm{v}}\right)$ and for a cow with a high $\mathrm{EBV}_{\mathrm{v}}$ for $\mathrm{C} 18: 1$ cis-9 content in milk ( $\mathrm{g} / \mathrm{dL}$ of milk).

data set. As illustrated, a cow with a high $\mathrm{EBV}_{\mathrm{v}}$ has a large variation of observations around the fitted mean curve during the lactation, whereas cow with low $\mathrm{EBV}_{\mathrm{v}}$ has low variation of observations around the mean curve during lactation. Figure 3 showed C18:1 cis-9 records from the daughters of 2 sires having at least 150 daughters with records and presenting the lowest and the highest $\mathrm{EBV}_{\mathrm{v}}$ for $\mathrm{C} 18: 1$ cis-9. As illustrated, the sire with the lowest $\mathrm{EBV}_{\mathrm{v}}$ had less variation in observations within its daughters group than the sire with the highest $\mathrm{EBV}_{\mathrm{v}}$.

In addition to genetic heterogeneity of residual variance, herd $\times$ test-day and permanent environmental effects contributed substantially to heterogeneity of re- sidual variance; that is, to a larger extent than genetics. Although $\sigma_{u_{v}}^{2}$ ranged between 0.014 and $0.029, \sigma_{h_{v}}^{2}$ and $\sigma_{p_{v}}^{2}$ ranged between 0.13 and 0.20 for herd $\times$ test-day effect and between 0.30 and 0.95 for permanent environmental effect (Table 2). The estimated fixed effects of DIM on residual variance were also high for all traits, especially in the beginning of lactation (Figure 4). Furthermore, the estimated fixed effects for DIM were twice as high for UFA and C18:1 cis-9 in the beginning of the lactation compared with the other traits. These higher variations could be explained by the fact that UFA and C18:1 cis-9 are more variable at the beginning of lactation than during the remainder of the lac-

\section{Low EBVv sire}

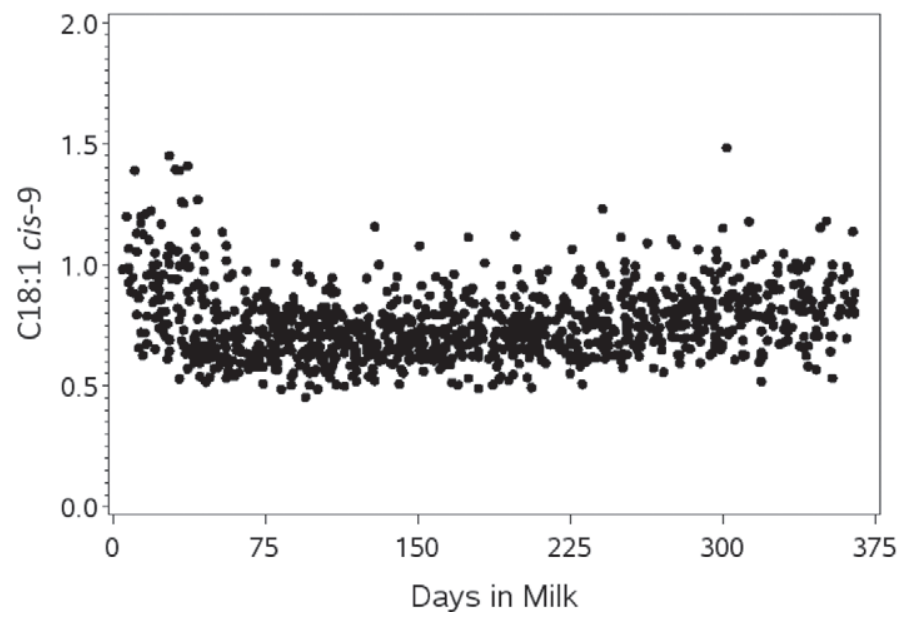

High EBVv sire

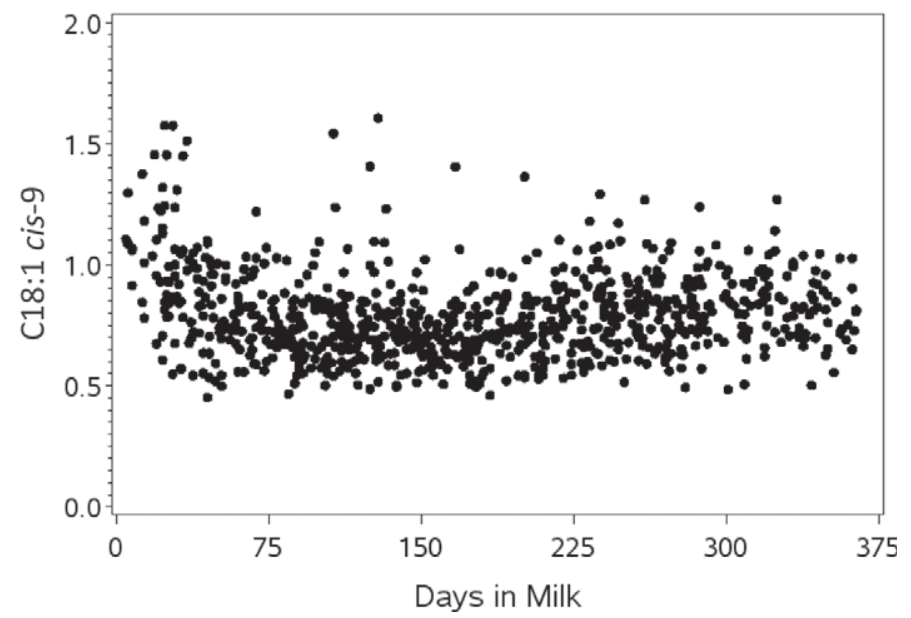

Figure 3. Observations of cows sired by 2 sires with a low or high EBV for the residual variance model $\left(\mathrm{EBV}_{\mathrm{v}}\right)$ and having each at least 150 daughters with records for $\mathrm{C} 18: 1$ cis-9 content in milk ( $\mathrm{g} / \mathrm{dL}$ of milk). 

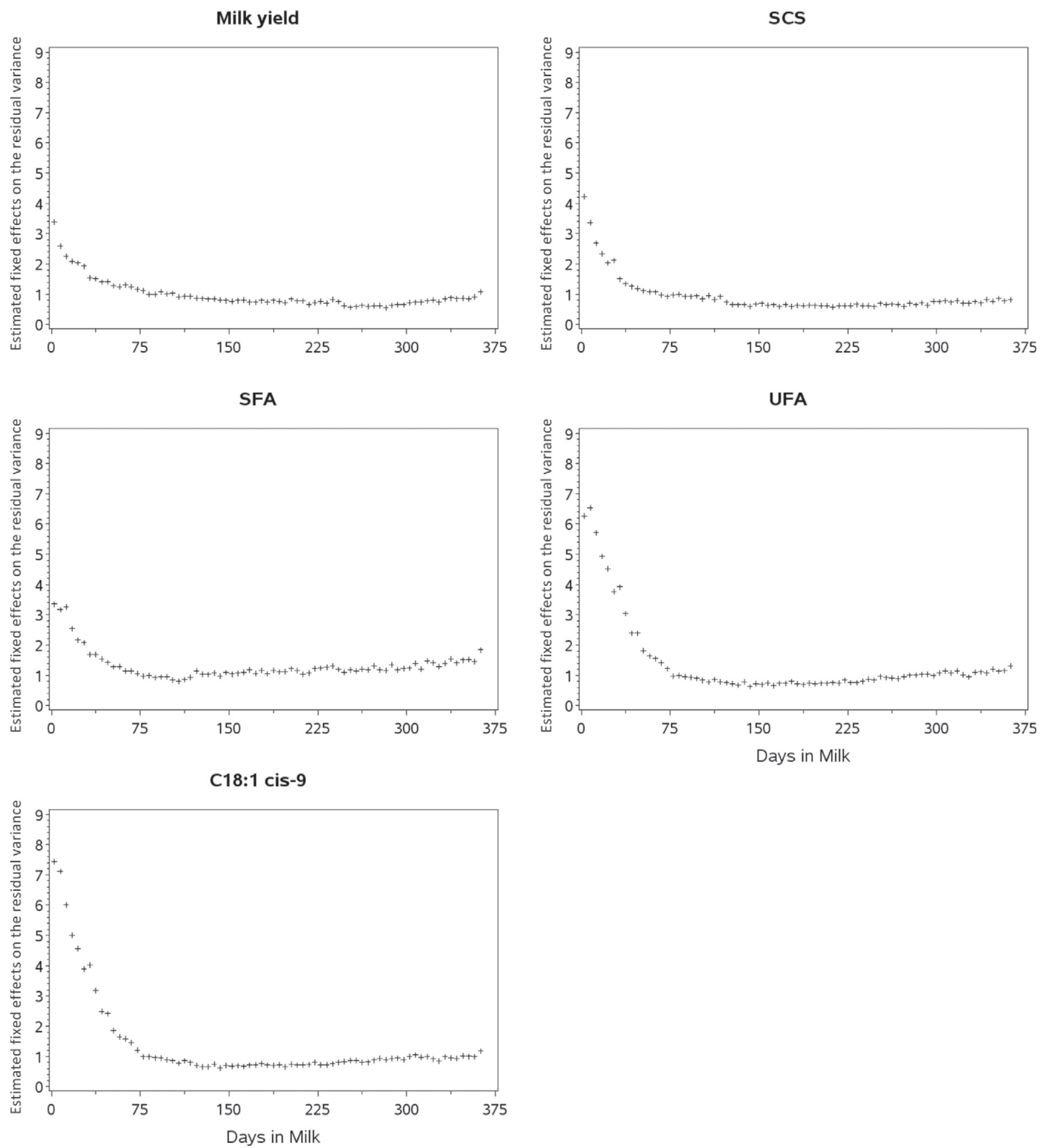

Figure 4. Estimated fixed effects of DIM on the residual variance for milk yield, SCS, SFA, unsaturated fatty acid (UFA), and C18:1 cis-9 contents in milk. 
UFA

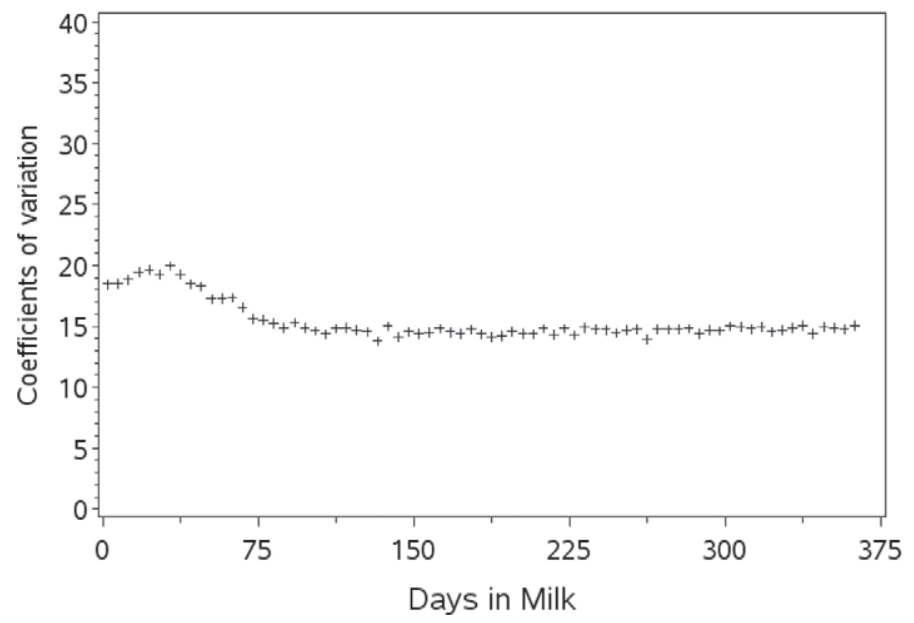

C18:1 cis-9

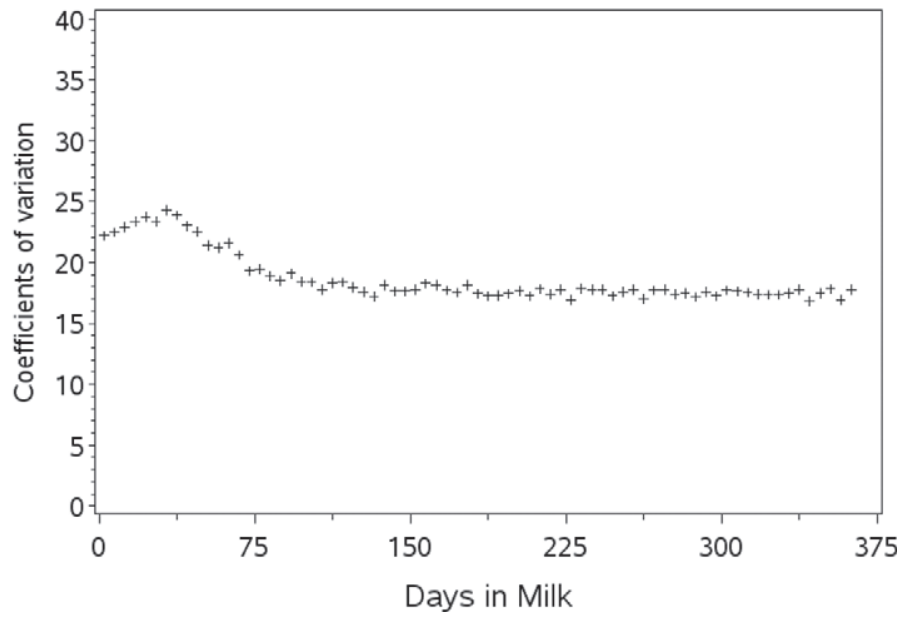

Figure 5. Coefficients of variation in function of 5 DIM classes for unsaturated fatty acid (UFA) and C18:1 cis-9 contents in milk.

tation (Figure 5), possibly because of differences among cows in body fat mobilization. The larger effect of DIM on the residual variance for UFA and C18:1 cis-9 in the beginning of the lactation could be related to the higher content of $\mathrm{C} 18 \mathrm{FA}$ in milk during the same period (Bastin et al., 2011) due to the release of mobilized body fat into the mammary gland when the cows are in negative energy balance (Barber et al., 1997). Such information about the nongenetic effects on residual variance could be interesting for management purposes. Therefore, the DHGLM method may provide valuable information to farmers about their management in terms of variation in addition to studying the genetic variance in residual variance and estimating $\mathrm{EBV}_{\mathrm{v}}$ to select for reduced environmental sensitivity in the studied traits.

\section{Pearson Correlations}

The DHGLM method as proposed by Rönnegård et al. (2010) did not allow the estimation of genetic correlations between $\mathbf{u}$ and $\mathbf{u}_{\mathbf{v}}$. However, they are relevant parameters (e.g., Sorensen and Waagepetersen, 2003), because they give information about possible evolution of the micro-environmental sensitivity due to a selection based on EBV, and vice versa. Thereby, genetic correlations between $\mathbf{u}$ and $\mathbf{u}_{\mathbf{v}}$ were approximated by Pearson correlation coefficients between EBV and $\mathrm{EBV}_{\mathrm{v}}$ obtained for sires with daughters and for cows with records for the 5 traits based on the estimations associated with the mean model [1] (Table 4). It should be noted that Pearson correlations for sires were similar to the corresponding ones for cows (Table 4).

Within traits, Pearson correlations between EBV and $\mathrm{EBV}_{\mathrm{v}}$ of sires having daughters with records ranged from 0.22 for $\mathrm{C} 18: 1$ cis-9 to 0.47 for milk yield. The corresponding estimates for cows with records ranged from 0.22 for SFA to 0.41 for milk yield. As shown by the $95 \%$ confidence intervals (Table 3 ), these Pearson correlations were different from zero $(P<0.001)$. Therefore, selection of animals with higher EBV for all studied traits would increase the residual variance as these animals would have also higher $\mathrm{EBV}_{\mathrm{v}}$ on average, especially for milk yield, which presented the highest correlation. Considering SCS, the positive correlation between EBV and $\mathrm{EBV}_{\mathrm{v}}(>0.23$; Table 4) is desirable, because selection for lower EBV of SCS would reduce the average level of SCS but also the residual variance of SCS, both implicating fewer mastitis cases. Rönnegård et al. (2013) also found positive correlations between EBV and $\mathrm{EBV}_{\mathrm{v}}$ for SCS and milk yield. As explained above, high contents in milk of C18:1 cis-9 in addition to small variation in this FA during lactation would be desirable. However, the selection of high EBV for this trait would increase its variation because of the positive correlation between EBV and $\mathrm{EBV}_{\mathrm{v}}(>0.22$; Table $4)$. Likewise, the selection of low $\mathrm{EBV}_{\mathrm{v}}$ would decrease the average content in milk of this FA. Nevertheless, the correlation differed from 1 , indicating that selection on both traits in the desired direction is feasible, but requires proper weighting of both EBV in total merit indices. This latter observation is true for all traits, because the correlations between EBV and $\mathrm{EBV}_{\mathrm{v}}$ were positive and low to moderate for all studied traits. This implied that selection of animals with reduced residual variance for 1 of these 5 traits has to be applied by considering both EBV and $\mathrm{EBV}_{\mathrm{v}}$ using index selection.

Among traits, Pearson correlations between EBV for milk yield and EBV for SFA, UFA, and C18:1 cis-9 ranged from -0.42 to $-0.56(P<0.001)$. These 
Table 4. Pearson correlation coefficients (95\% CI in parentheses) between EBV for the fixed lactation curve test-day mean model and EBV for the residual variance model (EBV $\left.\mathrm{v}_{\mathrm{v}}\right)$ for sires that have daughters with records (i.e., 523 sires) above the diagonal and for cows with records (i.e., 26,887 cows) below the diagonal for milk yield, SCS, SFA, unsaturated fatty acids (UFA), and C18:1 cis-9 contents in milk

\begin{tabular}{|c|c|c|c|c|c|c|c|c|c|c|}
\hline \multirow[b]{2}{*}{ Item } & \multicolumn{2}{|c|}{ Milk yield } & \multicolumn{2}{|c|}{ SCS } & \multicolumn{2}{|c|}{ SFA } & \multicolumn{2}{|c|}{ UFA } & \multicolumn{2}{|c|}{ C18:1 cis-9 } \\
\hline & EBV & $\mathrm{EBV}_{\mathrm{v}}$ & EBV & $\mathrm{EBV}_{\mathrm{v}}$ & EBV & $\mathrm{EBV}_{\mathrm{v}}$ & EBV & $\mathrm{EBV}_{\mathrm{v}}$ & EBV & $\mathrm{EBV}_{\mathrm{v}}$ \\
\hline \multicolumn{11}{|l|}{ Milk yield } \\
\hline $\mathrm{EBV}$ & 1.00 & $\begin{array}{l}0.47 \\
(0.40,0.54)\end{array}$ & $\begin{array}{l}0.00 \\
(-0.09,0.09)\end{array}$ & $\begin{array}{l}0.19 \\
(0.10,0.27)\end{array}$ & $\begin{array}{l}-0.52 \\
(-0.58,-0.45)\end{array}$ & $\begin{array}{l}-0.34 \\
(-0.41,-0.26)\end{array}$ & $\begin{array}{l}-0.56 \\
(-0.62,-0.50)\end{array}$ & $\begin{array}{l}-0.15 \\
(-0.23,-0.06)\end{array}$ & $\begin{array}{l}-0.49 \\
(-0.55,-0.42)\end{array}$ & $\begin{array}{l}-0.15 \\
(-0.23,-0.07)\end{array}$ \\
\hline $\mathrm{EBV}_{\mathrm{v}}$ & $\begin{array}{l}0.41 \\
(0.40,0.42)\end{array}$ & 1.00 & $\begin{array}{l}0.08 \\
(0.00,0.17)\end{array}$ & $\begin{array}{l}0.19 \\
(0.10,0.27)\end{array}$ & $\begin{array}{l}-0.32 \\
(-0.39,-0.24)\end{array}$ & $\begin{array}{l}-0.01 \\
(-0.10,0.07)\end{array}$ & $\begin{array}{l}-0.28 \\
(-0.35,-0.19)\end{array}$ & $\begin{array}{l}0.12 \\
(0.03,0.20)\end{array}$ & $\begin{array}{l}-0.20 \\
(-0.28,-0.12)\end{array}$ & $\begin{array}{l}0.05 \\
(-0.04,0.14)\end{array}$ \\
\hline \multicolumn{11}{|c|}{ 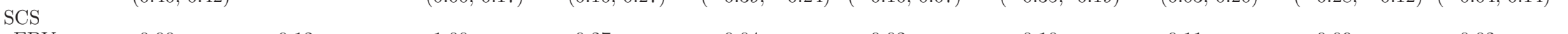 } \\
\hline EBV & $\begin{array}{l}0.00 \\
(-0.01,0.01)\end{array}$ & $\begin{array}{l}0.12 \\
(0.11,0.14)\end{array}$ & 1.00 & $\begin{array}{l}0.27 \\
(0.19,0.35)\end{array}$ & $\begin{array}{l}-0.04 \\
(-0.13,0.05)\end{array}$ & $\begin{array}{l}-0.02 \\
(-0.11,0.06)\end{array}$ & $\begin{array}{l}0.10 \\
(0.01,0.19)\end{array}$ & $\begin{array}{l}0.11 \\
(0.03,0.20)\end{array}$ & $\begin{array}{l}0.09 \\
(0.01,0.18)\end{array}$ & $\begin{array}{l}0.02 \\
(-0.06,0.11)\end{array}$ \\
\hline $\mathrm{EBV}_{\mathrm{v}}$ & $\begin{array}{l}0.16 \\
(0.15,0.17)\end{array}$ & $\begin{array}{l}0.26 \\
(0.25,0.27)\end{array}$ & $\begin{array}{l}0.23 \\
(0.21,0.24)\end{array}$ & 1.00 & $\begin{array}{l}-0.18 \\
(-0.26,-0.10)\end{array}$ & $\begin{array}{l}0.12 \\
(0.03,0.20)\end{array}$ & $\begin{array}{l}-0.18 \\
(-0.27,-0.10)\end{array}$ & $\begin{array}{l}0.04 \\
(-0.05,0.12)\end{array}$ & $\begin{array}{l}-0.14 \\
(-0.23,-0.06)\end{array}$ & $\begin{array}{l}-0.06 \\
(-0.14,0.03)\end{array}$ \\
\hline \multicolumn{11}{|c|}{ ( } \\
\hline EBV & $\begin{array}{l}-0.42 \\
(-0.43,-0.41)\end{array}$ & $\begin{array}{l}-0.24 \\
(-0.25,-0.23)\end{array}$ & $\begin{array}{l}-0.06 \\
(-0.07,-0.05)\end{array}$ & $\begin{array}{l}-0.11 \\
(-0.12,-0.09)\end{array}$ & 1.00 & $\begin{array}{l}0.28 \\
(0.20,0.36)\end{array}$ & $\begin{array}{l}0.71 \\
(0.66,0.75)\end{array}$ & $\begin{array}{l}0.14 \\
(0.05,0.22)\end{array}$ & $\begin{array}{l}0.62 \\
(0.57,0.67)\end{array}$ & $\begin{array}{l}0.18 \\
(0.09,0.26)\end{array}$ \\
\hline $\mathrm{EBV}_{\mathrm{v}}$ & $\begin{array}{l}-0.27 \\
(-0.28,-0.26)\end{array}$ & $\begin{array}{l}-0.04 \\
(-0.05,-0.02)\end{array}$ & $\begin{array}{l}-0.05 \\
(-0.06,-0.03)\end{array}$ & $\begin{array}{l}0.25 \\
(0.24,0.26)\end{array}$ & $\begin{array}{l}0.22 \\
(0.20,0.23)\end{array}$ & 1.00 & $\begin{array}{l}0.23 \\
(0.14,0.31)\end{array}$ & $\begin{array}{l}0.43 \\
(0.35,0.50)\end{array}$ & $\begin{array}{l}0.20 \\
(0.12,0.28)\end{array}$ & $\begin{array}{l}0.39 \\
(0.32,0.47)\end{array}$ \\
\hline \multicolumn{11}{|c|}{ 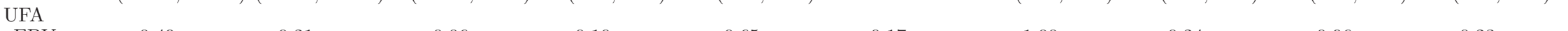 } \\
\hline EBV & $\begin{array}{l}-0.49 \\
(-0.50,-0.48)\end{array}$ & $\begin{array}{l}-0.21 \\
(-0.22,-0.20)\end{array}$ & $\begin{array}{l}0.06 \\
(0.05,0.07)\end{array}$ & $\begin{array}{l}-0.10 \\
(-0.11,-0.09)\end{array}$ & $\begin{array}{l}0.65 \\
(0.64,0.66)\end{array}$ & $\begin{array}{l}0.17 \\
(0.16,0.18)\end{array}$ & 1.00 & $\begin{array}{l}0.24 \\
(0.15,0.32)\end{array}$ & $\begin{array}{l}0.96 \\
(0.95,0.96)\end{array}$ & $\begin{array}{l}0.23 \\
(0.15,0.31)\end{array}$ \\
\hline $\mathrm{EBV}_{\mathrm{v}}$ & $\begin{array}{l}-0.13 \\
(-0.14,-0.12)\end{array}$ & $\begin{array}{l}0.11 \\
(0.10,0.13)\end{array}$ & $\begin{array}{l}0.16 \\
(0.14,0.17)\end{array}$ & $\begin{array}{l}0.10 \\
(0.09,0.11)\end{array}$ & $\begin{array}{l}0.10 \\
(0.09,0.11)\end{array}$ & $\begin{array}{l}0.38 \\
(0.37,0.39)\end{array}$ & $\begin{array}{l}0.23 \\
(0.22,0.24)\end{array}$ & 1.00 & $\begin{array}{l}0.23 \\
(0.14,0.31)\end{array}$ & $\begin{array}{l}0.93 \\
(0.91,0.94)\end{array}$ \\
\hline \multicolumn{11}{|l|}{ C18:1 cis-9 } \\
\hline EBV & $\begin{array}{l}-0.46 \\
(-0.47,-0.45)\end{array}$ & $\begin{array}{l}-0.16 \\
(-0.17,-0.15)\end{array}$ & $\begin{array}{l}0.04 \\
(0.03,0.06)\end{array}$ & $\begin{array}{l}-0.07 \\
(-0.09,-0.06)\end{array}$ & $\begin{array}{l}0.56 \\
(0.55,0.57)\end{array}$ & $\begin{array}{l}0.17 \\
(0.16,0.18)\end{array}$ & $\begin{array}{l}0.95 \\
(0.95,0.95)\end{array}$ & $\begin{array}{l}0.24 \\
(0.22,0.25)\end{array}$ & 1.00 & $\begin{array}{l}0.22 \\
(0.13,0.30)\end{array}$ \\
\hline $\mathrm{EBV}_{\mathrm{v}}$ & $\begin{array}{l}-0.14 \\
(-0.15,-0.12)\end{array}$ & $\begin{array}{l}0.06 \\
(0.05,0.08)\end{array}$ & $(0.06,0.08)$ & $\begin{array}{l}0.03 \\
(0.02,0.05)\end{array}$ & $(0.11,0.14)$ & $\begin{array}{l}0.33 \\
(0.32,0.34)\end{array}$ & $\begin{array}{l}0.23 \\
(0.22,0.25)\end{array}$ & $\begin{array}{l}0.93 \\
(0.93,0.93)\end{array}$ & $\begin{array}{l}0.24 \\
(0.23,0.25)\end{array}$ & 1.00 \\
\hline
\end{tabular}


correlations were of the same order of magnitude although slightly higher than the corresponding average daily genetic correlations approximated by Bastin et al. (2011) on similar data. Genetic correlation estimates from Bastin et al. (2011) were approximated as average correlations between daily EBV and ranged between -0.35 and -0.40 . These results could be explained by the difference between the mean model [1] (i.e., a fixed lactation curve test-day model) and the random regressions test-day model used by Bastin et al. (2011). Indeed, using the approach proposed by Bastin et al. (2011) and based on the daily EBV estimated from the mean model [2] (i.e., random regression test-day model), genetic correlation estimates between milk yield and SFA, UFA, and C18:1 cis-9 ranged from -0.35 to -0.50 (results not shown). The remaining difference could be explained by another difference between models; that is, the genetic heterogeneity of residual variance in this study. However, it should be noted that approximated genetic correlations associated with the mean model [2] followed the same trends as Pearson correlations associated with the mean model [1] (results not shown). Pearson correlations among EBV for SFA, UFA, and C18:1 cis-9 ranged from 0.56 to 0.96 in the present study. Bastin et al. (2011) estimated similar average daily genetic correlations (i.e., between 0.51 and 0.96) for the same combinations of FA. Both Pearson correlations between EBV for milk yield and EBV for SCS were equal to 0.00 (Table 4). Although genetic correlations between milk yield and SCS are usually expected to be unfavorable for the first parity (e.g., Boettcher et al., 1992), Pösö and Mäntysaari (1996) estimated genetic correlations that did not significantly differ from zero.

Pearson correlations between EBV as well as between $\mathrm{EBV}_{\mathrm{v}}$ of UFA and C18:1 cis-9 were high $(\geq 0.93$; Table 4), because C18:1 cis-9 is highly represented in UFA (Table 1). This high proportion of C18:1 cis-9 in UFA also led to similar correlations (about 0.23; Table 4) between $\mathrm{EBV}$ and $\mathrm{EBV}_{\mathrm{v}}$ of each trait or between traits. Hence, the residual variance for both traits would increase if animals with high EBV are selected for only 1 of these 2 traits.

\section{CONCLUSIONS}

The study of genetic variance in micro-environmental sensitivity through the estimation of variance components and breeding values in residual variance for milk yield, SCS, SFA, UFA, and C18:1 cis-9 for first-parity Holstein cows in the Walloon Region of Belgium showed the presence of genetic and nongenetic heterogeneity of residual variance for the 5 traits. Although $h_{v}^{2}$ and GCV were lower than or corresponded to the lower range of other species, some genetic variance in environmental sensitivity existed in the Walloon Holstein dairy cattle, indicating that micro-environmental sensitivity could be changed by selection. For all traits, Pearson correlations between $\mathrm{EBV}$ and $\mathrm{EBV}_{\mathrm{v}}$ were positive and low to moderate. Selection for animals robust to micro-environmental sensitivity is therefore feasible with proper weighing of both EBV in total merit indices, even if positive correlations were not favorable for some traits (e.g., C18:1 cis-9). Nongenetic effects also contributed substantially to the micro-environmental sensitivity following variance components for herd $\times$ test-day and permanent environmental effects as well as the estimated fixed effects of DIM on residual variance. Therefore, in addition to provide information to select for changes in micro-environmental sensitivity, the DHGLM method may provide information for management purposes in terms of variation.

\section{ACKNOWLEDGMENTS}

This project was financed by the RobustMilk project (www.robustmilk.eu), which was financially supported by the European Commission under the Seventh Research Framework Programme, Grant Agreement KBBE-211708. The content of this paper is the sole responsibility of the authors and it does not necessarily represent the views of the Commission or its services. Jérémie Vandenplas, as a research fellow, acknowledges the support of the National Fund for Scientific Research (Brussels, Belgium) for his position. Additional financial support was provided by the Ministry of Agriculture of Walloon Region of Belgium (Service Public de Wallonie, Direction générale opérationnelle "Agriculture, Ressources naturelles et Environnement" - DGA-RNE) through research projects D31-1207, D31-1224, and D31-1273. Jérémie Vandenplas acknowledges Shogo Tsuruta (University of Georgia, Athens) for his comments concerning the computations of log REML. The authors are grateful to University of Liege (SEGI facility, Liege, Belgium) for the use of NIC3 supercomputer and to two anonymous reviewers for the useful comments.

\section{REFERENCES}

Akaike, H. 1973. Information theory and an extension of the maximum likelihood principle. Pages 267-281 in 2nd Int. Symp. Information Theory. B. N. Petrov and F. Csaki, ed. Akademiai Kiado, Budapest, Hungary.

Barber, M. C., R. A. Clegg, M. T. Travers, and R. G. Vernon. 1997. Lipid metabolism in the lactating mammary gland. Biochim. Biophys. Acta 1347:101-126.

Bastin, C., D. Berry, H. Soyeurt, and N. Gengler. 2012. Genetic correlations of days open with production traits and contents in milk of major fatty acids predicted by mid-infrared spectrometry. J. Dairy Sci. 95:6113-6121. 
Bastin, C., N. Gengler, and H. Soyeurt. 2011. Phenotypic and genetic variability of production traits and milk fatty acid contents across days in milk for Walloon Holstein first-parity cows. J. Dairy Sci. 94:4152-4163.

Boettcher, P. J., L. B. Hansen, P. M. VanRaden, and C. A. Ernst 1992. Genetic evaluation of Holstein bulls for somatic cells in milk of daughters. J. Dairy Sci. 75:1127-1137.

Felleki, M., D. Lee, Y. Lee, A. R. Gilmour, and L. Rönnegård. 2012. Estimation of breeding values for mean and dispersion, their variance and correlation using double hierarchical generalized linear models. Genet. Res. (Camb.) 94:307-317.

Haug, A., A. T. H. Østmark, and O. M. Harstad. 2007. Bovine milk in human nutrition-A review. Lipids Health Dis. 6:25.

Hill, W. G., and H. A. Mulder. 2010. Genetic analysis of environmental variation. Genet. Res. (Camb.) 92:381-395.

Lee, Y., and J. A. Nelder. 2006. Double hierarchical generalized linear models. Appl. Stat. 55:139-185.

Meuwissen, T. H. E., G. De Jong, and B. Engel. 1996. Joint estimation of breeding values and heterogeneous variances of large data files. J. Dairy Sci. 79:310-316.

Misztal, I. 2012. BLUPF90 family of programs. University of Georgia, Athens. Accessed Dec. 19, 2012. http://nce.ads.uga.edu/wiki/ doku.php.

Mulder, H. A., P. Bijma, and W. G. Hill. 2007. Prediction of breeding values and selection responses with genetic heterogeneity of environmental variance. Genetics 175:1895-1910.

Mulder, H. A., P. Bijma, and W. G. Hill. 2008. Selection of uniformity in livestock by exploiting genetic heterogeneity of residual variance. Genet. Sel. Evol. 40:37-59.

Mulder, H. A., W. G. Hill, A. Vereijken, and R. F. Veerkamp. 2009. Estimation of genetic variation in residual variance in female and male broilers. Animal 3:1673-1680.

Mulder, H. A., L. Rönnegård, W. F. Fikse, R. F. Veerkamp, and E. Strandberg. 2013. Estimation of genetic variance for macro- and micro-environmental sensitivity using double hierarchical generalized linear models. Genet. Sel. Evol. 45:23.
Palmquist, D. L., A. D. Beaulieu, and D. M. Barbano. 1993. Feed and animal factors influencing milk fat composition. J. Dairy Sci. 76:1753-1771.

Pösö, J., and E. A. Mäntysaari. 1996. Relationships between clinical mastitis, somatic cell score and production for the first three lactations of Finnish Ayrshire. J. Dairy Sci. 79:1284-1291.

Rönnegård, L., M. Felleki, F. Fikse, H. Mulder, and E. Strandberg. 2010. Genetic heterogeneity of residual variance-Estimation of variance components using double hierarchical generalized linear models. Genet. Sel. Evol. 42:8-18.

Rönnegård, L., M. Felleki, W. F. Fikse, H. Mulder, and E. Strandberg. 2013. Variance component and breeding value estimation for genetic heterogeneity of residual variance in Swedish Holstein dairy cattle. J. Dairy Sci. 96:2627-2636. http://dx.doi.org/10.3168/ jds.2012-6198.

Rönnegård, L., W. F. Fikse, H. A. Mulder, and E. Strandberg. 2011. Breeding value estimation for environmental sensitivity on a large dairy cattle dataset. Interbull Bull. 44:110-113.

SanCristobal-Gaudy, M., L. Bodin, J. M. Elsen, and C. Chevalet. 2001. Genetic components of litter size variability in sheep. Genet. Sel. Evol. 33:249-271.

Schwarz, G. 1978. Estimating the dimension of a model. Ann. Stat. 6:461-464

Sorensen, D., and R. Waagepetersen. 2003. Normal linear models with genetically structured residual variance heterogeneity: A case study. Genet. Res. 82:207-222.

Soyeurt, H., F. Dehareng, N. Gengler, S. McParland, E. Wall, D. P. Berry, M. Coffey, and P. Dardenne. 2011. Mid-infrared prediction of bovine milk fatty acids across multiple breeds, production systems, and countries. J. Dairy Sci. 94:1657-1667.

Van Vleck, L. D. 1993. Selection Index and Introduction to Mixed Model Methods for Genetic Improvement of Animals. CRC Press, Boca Raton, FL.

Williams, C. M. 2000. Dietary fatty acids and human health. Ann. Zootech. 49:165-180. 